\title{
Chiral Quaternary Carbon Stereocenters via Diene-yne [2+2+2] Cycloaddition
}

Metal-Catalyzed Asymmetric Synthesis and Stereoselective

Reactions

\section{Key words}

rhodium(I)

chiral quaternary carbon stereocenter

ToIBINAP
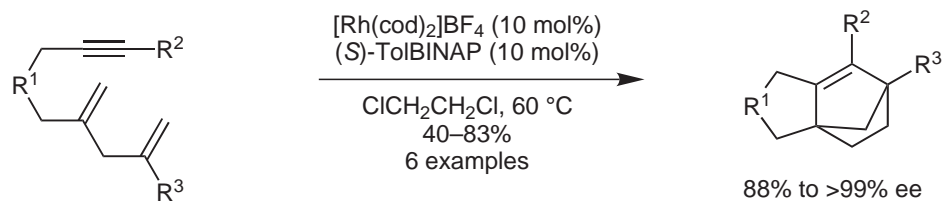

$88 \%$ to $>99 \%$ ee
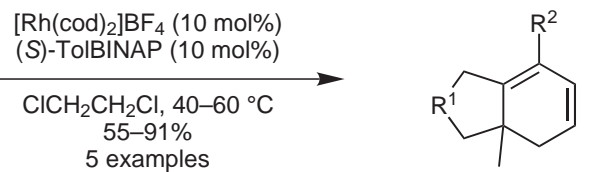

$92 \%$ to $>99 \%$ ee

$\mathrm{R}^{1}=\mathrm{NTs}, \mathrm{C}\left(\mathrm{CO}_{2} \mathrm{Bn}\right)_{2}, \mathrm{O}$

$\mathrm{R}^{2}=\mathrm{H}, \mathrm{Ar}$, Alk

$\mathrm{R}^{3}=\mathrm{Me}, \mathrm{Ph}$

Proposed mechanism:

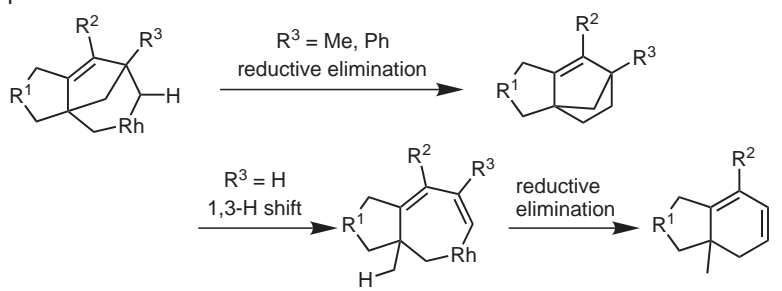

Significance: In the presence of a $\left[\mathrm{Rh}(\operatorname{cod})_{2}\right] \mathrm{BF}_{4} /$ Tol-BINAP catalyst system, diene-ynes can be converted into either chiral substituted norbornenes or chiral bicyclic dienes in one step with excellent enantioselectivity and good to excellent yield. The key to the divergent product selectivity is the diene substitutent $R^{3}$, which is proposed to control the mechanism of the final bond-forming step. The reaction was also performed under an acetylene atmosphere, forming an allyl diene product in low yield.
Comment: Rhodium-catalyzed [2+2+2] cyclization reactions are novel methods for generating complex aromatic and alicyclic products (see review below). The method of Shibata and Tahara is particularly interesting, as the product can either be a strained alkene or a chiral diene, with one or more chiral quaternary carbon stereocenters. With regard to the dienyl product, the proposed mechanism includes a 1,3-H shift when $\mathrm{R}^{3}=\mathrm{H}$, allowing formation of a dienylrhodium species which reductively eliminates to form the dienyl product; however, no isotopic labeling studies were performed to support this mechanism.

Review: S. Kotha, E. Brahmachary, K. Lahiri Eur. J. Org. Chem. 2005, 4741-4767. 